\title{
Pioneras de la arquitectura ecuatoriana
}

\author{
Verónica Alexandra Rosero Añazco', 2 (i) 0000-0002-3257-619X \\ María José Freire Silva ${ }^{2}$ (D) 0000-0002-4543-1504 \\ 'Universidad Internacional SEK, Quito, Pichincha, Ecuador. \\ 170134 -admisiones@uisek.edu.ec \\ 2Universidad Central del Ecuador, Quito, Pichincha, Ecuador. \\ 170521 - uce.informacion1@uce.edu.ec
}

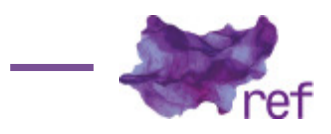

\begin{abstract}
Resumen: La investigación "Pioneras de la arquitectura ecuatoriana" propone una búsqueda histórica para reconocer y visibilizar a las mujeres que han contribuido a la arquitectura en Ecuador hasta 1980. La detección de perfiles relevantes se realizó mediante la revisión de archivos de las primeras facultades de arquitectura del país y de bibliografía local especializada, complementando datos cuantitativos con entrevistas. La mirada feminista con la que se abordó el estudio cuestiona la profesión no solo desde la perspectiva de género, sino desde sus estructuras que resaltan sólo contribuciones tangibles. Este texto, mediante una discusión crítica, reivindica la producción intelectual de la primera generación de arquitectas, quienes destacaron principalmente en la academia, historia y teoría.
\end{abstract}

Palabras clave: arquitectura; feminismo; Ecuador; pioneras del siglo XX; historia.

The Women Pioneers of Ecuadorian Architecture

Abstract: The research "Women Pioneers of Ecuadorian Architecture" proposes a historical review to recognize and make visible the women who have contributed to architecture in Ecuador until 1980. Relevant profiles were searched through the review of archives of the first architecture faculties of the country and specialized local bibliography, complementing quantitative data with interviews. The feminist point of view addressed by the study questions the profession not only from a gender perspective, but also from its established structures that highlight only tangible contributions. Through a critical discussion, this text claims the intellectual production of the first generation of women architects, who mainly distinguished in academia, history, and theory.

Keywords: Architecture; Feminism; Ecuador; 20th Century Women Pioneers; History.

\section{As mulheres pioneiras da arquitetura equatoriana}

Resumo: A pesquisa "Mulheres pioneiras da arquitetura equatoriana" propõe uma revisão histórica para reconhecer e tornar visíveis as mulheres que contribuíram para a arquitetura no Equador até 1980. A investigação envolveu uma revisão dos arquivos das primeiras faculdades de arquitetura do país e bibliografia local especializada para a detecção de perfis relevantes. Os dados quantitativos foram complementados com entrevistas que forneceram informações qualitativas. O ponto de vista feminista abordado pelo estudo questiona a profissão não apenas da perspectiva de gênero, mas de suas estruturas estabelecidas que destacam apenas contribuições tangíveis. Este texto, com uma discussão crítica, reivindica a produção intelectual da primeira geração de mulheres arquitetas, que se destacaram principalmente na docência universitária, história e teoria.

Palavras-chave: arquitetura; feminismo; Equador; mulheres pioneiras do século XX; história.

\section{Una mirada feminista a la arquitectura en Ecuador del siglo XX}

El inicio del siglo XXI se caracterizó por el estallido de dos olas feministas, otorgando fuerza al papel de la mujer en la construcción de la sociedad, con una importante presencia a través de nuevos medios y tácticas como lo explica el artículo \#MeTooArchitecture: 
La revolución feminista está en marcha y es visible a través de la resonancia promovida en red desde distintos ámbitos; no ya desde la cultura humanista e ilustrada, sino desde lugares, acciones, términos y temporalidades diversas, híbridas, compartidas y mutantes en los que la Arquitectura es solo un término más después de un hashtag." (Atxu AMANN, et.al., 2018, p. 206)

Los estudios de género revelan nuevas realidades y apuestan por reconstruir la historia desde una nueva perspectiva, a través de la revisión del pasado para comprender la complejidad del espacio construido, históricamente narrado desde los aportes masculinos. Es fundamental comprender que las aproximaciones feministas aspiran a crear discursos complementarios que enriquezcan las referencias del contexto estudiado. Esta perspectiva propone un cambio de paradigma en la arquitectura, desde y con los feminismos, con el objeto de "transformar los supuestos establecidos en la práctica profesional, el trabajo académico y el imaginario colectivo" (Daniela ARIAS; Zaida MUXÍ, 2018, p. 5-6). En este marco, surge "Pioneras de la arquitectura ecuatoriana", apostando por reconstruir el imaginario colectivo de la arquitectura local, cuestionándolo no sólo desde la perspectiva de género, sino desde las estructuras de la profesión que mediatizan aportes masculinos desde el paradigma del diseño, omitiendo campos relevantes como la teoría e historia, patrimonio, urbanismo, gestión pública, entre otros ámbitos.

¿Por qué pioneras? En 1975 la arquitecta argentina Evelia Peralta llega a Ecuador. Junto a Rolando Moya funda la revista Trama (1977), primera publicación especializada en arquitectura del país. Ellos acuñaron el título "Ios pioneros de la arquitectura ecuatoriana" (Evelia PERALTA; Rolando MOYA, 2011, p.78-87) al ver la calidad de una producción que poca difusión había recibido hasta el momento. Esta investigación se apropia del título y lo feminiza para devolverlo a un grupo de arquitectas, pioneras en la producción del pensamiento arquitectónico desde la segunda mitad del siglo XX. Tras una revisión historiográfica se encontró a una serie de profesionales, ecuatorianas y extranjeras, que adquirieron relevancia en el contexto ecuatoriano. Para la delimitación temporal se tomó como punto de inicio los años de fundación de las primeras facultades de arquitectura en Guayaquil, Quito y Cuenca. Como punto de cierre se establece el año 1980, ya que en 1981 el libre acceso a la universidad pública aumentó exponencialmente el número de estudiantes, lo que amerita otra etapa de estudio. La revisión documental y bibliográfica en sus archivos permitió obtener datos cuantitativos complementados con información cualitativa obtenida de entrevistas. Esto permitió realizar una lectura crítica, que pone en valor el pasado y plantea nuevas perspectivas para una profesión con participación femenina en aumento.

\section{Las primeras facultades y la primera generación de arquitectas}

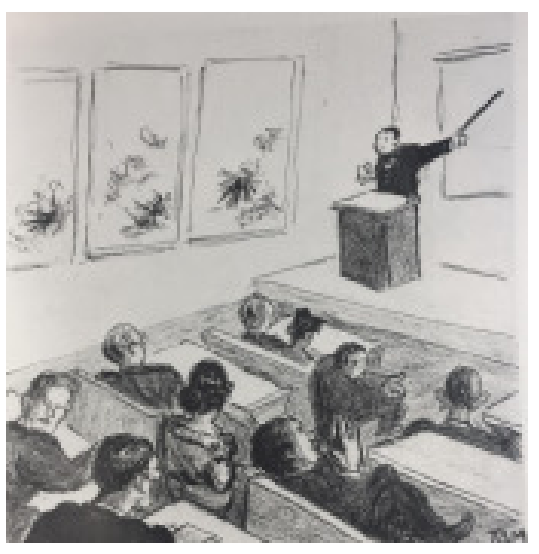

Imagen 1. Profesor Cyrano Tama. Primeros alumnos en arquitectura; al centro está Otilia Plaza, 1931.

Fuente: Compte, Florencio, 2017, p. 7-17.

\#PraTodoMundoVer Dibujo de un aula con profesor dirigiéndose a estudiantes, entre ellos está solo una mujer en el centro. El aula posee un pizarrón al frente y al lado izquierdo unas ventanas.

En Guayaquil se abre en 1929 la Escuela de Arquitectura en la Facultad de Ingeniería de la Universidad de Guayaquil (UG) (pública). En 1930 ingresa la primera promoción con nueve estudiantes, entre ellos una sola mujer: Otilia Plaza, quien no terminó su carrera. En 1933 se divide la facultad entre arquitectura e ingeniería, pero recién en la década de 1960 ingresan varias mujeres. En 1970 aparecen las primeras tituladas: 25 en la UG y dos en la Universidad Católica Santiago de Guayaquil (UCSG) (privada).

En Quito, la Facultad de Ciencias Matemáticas de la Universidad Central del Ecuador (UCE) (pública) graduaba ingenieros arquitectos, desde 1911, hasta la creación de la carrera de arquitectura en 1946, adscrita a la Facultad de Ingeniería. En 1959 se crea la Facultad de Arquitectura y Urbanismo (FAU), y en la década de 1960 ingresa el primer grupo femenino, con ocho integrantes. En 1967, Cecilia Rosales, colombiana, fue la primera mujer en recibir el título de arquitecta en Ecuador.

En Cuenca, la Escuela de Arquitectura en la Universidad de Cuenca (UCUENCA) (pública), adscrita a la Facultad de Ciencias Matemáticas, nace en 1958 y en 1961 se separa como Facultad de Arquitectura y Urbanismo. En 1963, la quiteña Lupe Ibarra se matricula en esta carrera y se titula en 1970. Lupe, junto a sus 27 colegas de Guayaquil, forma parte del primer grupo de arquitectas del país.

Eventos relevantes: El acceso de mujeres a las universidades ecuatorianas se inicia en la primera mitad del siglo XX. Destaca Matilde Hidalgo, primera mujer en estudiar una carrera 
universitaria (Medicina, UCuenca, 1921) y en sufragar (1924) (Erika VILLEGAS, 2013, p.10). La incorporación femenina a la carrera de arquitectura es, sin embargo, tardía y lenta: pasaron casi cinco décadas hasta contar con una mujer titulada. La presencia de la mujer en los primeros años de conformación de las facultades es prácticamente anecdótica, a excepción del caso de la UG. Las causas son de índole político y sociocultural. Político porque el acceso de la mujer a la educación dependió de políticas públicas para su incursión. Social, dada la estructura de un país conservador como el Ecuador, pese a que el proyecto liberal y la educación laica abrieron nuevas posibilidades de participación en la vida pública (Ana María GOETSCHEL, 2007, p. 18-19).

A esto se suma: una combinación de estereotipos y prejuicios sobre las carreras tecnológicas (entre ellas arquitectura), la falta de referentes femeninos, y los roles (preasignados a la mujer) de cuidado del hogar y de personas dependientes. Desde el ámbito de la docencia universitaria, también se observa una escasa participación femenina. En Ecuador, la primera mujer en ejercer este rol en arquitectura fue Guadalupe Ibarra, quien se incorporó al profesorado después de su graduación. En Quito, en 1971, Mélida Estrada ingresa a la UCE como primera mujer docente (Franklin CARCELÉN, 2019). En 1972 Ángeles Martín fue la primera docente en la UG. Tanto las primeras graduadas como las primeras docentes representan hitos en la formación académica y sientan las bases para las siguientes generaciones que paulatinamente ven la presencia de la mujer en la carrera sin sesgos. (Gráfico 1). Sin embargo, es preciso no olvidar los retos que asumieron las generaciones precedentes, así como los actuales altos índices de "techo de cristal" que muestran la existencia de una barrera "invisible" que impide a una mujer ascender en su carrera profesional a cargos que impliquen toma de decisiones, debido a sesgos y/o roles de género, pese a estar igualmente calificada que un hombre.

Las primeras tituladas. Según las actas revisadas, el primer título de arquitectura para una mujer en Ecuador se expide en 1967 a la colombiana Cecilia Rosales, en la UCE. Según testimonio de Milton Barragán, una vez graduada, Rosales viajó a Francia para continuar sus estudios y se estableció en ese país, donde ejerció durante varios años la profesión. Más tarde regresó a Ecuador y retomó contacto con Barragán, con quien trabajó en varios proyectos. Barragán comenta que en sus años de estudio él compartió aulas con dos mujeres, una ecuatoriana (Julia Albuja) y una chilena (no recuerda su nombre) (Milton BARRAGÁN, 2019). No obstante, en las actas de grado originales y bases de datos de trabajos de titulación revisadas no hay registro de su graduación, siendo este un vacío pendiente por llenar. De Julia Albuja se sabe que fue parte de los fundadores del Colegio de Arquitectos:

En mayo de 1962, los profesionales y egresados de la Escuela de Arquitectura fuimos convocados a una sesión solemne (...). Allí se decidió la conformación del Colegio. Junto a un grupo de unas cincuenta personas, fui la única mujer en tan importante acto fundacional. (EL COMERCIO, 2012).

Según las evidencias disponibles, las primeras mujeres ecuatorianas que obtuvieron el título de arquitectas se graduaron en 1970 en las Universidades de Guayaquil y Cuenca. El porcentaje de arquitectas tituladas varía entre las regiones de sierra y costa, evidenciando contextos socioculturales diferentes (Tabla 3): las ciudades de Quito y Cuenca presentan 6 a $7 \%$ de participación femenina versus un 22 a 35\% en Guayaquil (Gráfico 2). De estos datos se puede inferir que la ciudad portuaria de Guayaquil, históricamente relacionada a una sociedad más liberal en términos políticos, presentó mayor apertura a la incursión de la mujer en carreras universitarias y el respectivo ejercicio de la profesión. En efecto, Rosa Rada, titulada en la década de 1970 en UCSG, fue la primera mujer en acceder al cargo de decana de una Facultad de Arquitectura en el Ecuador en 2008.

\section{La presencia en los medios de difusión}

Para la detección de perfiles relevantes se revisaron varios medios de difusión de consulta frecuente en las facultades de arquitectura local, realizando un corte hasta 1999, año en que la crisis frenó la producción de muchos profesionales vinculados al sector de la construcción. Si bien el estudio de las pioneras se centra en los personajes titulados hasta 1980, su presencia en medios en las décadas posteriores a la obtención de su grado universitario es la evidencia de su ejercicio sostenido en la profesión.

\section{Revistas especializadas}

Revista Trama (1977 a 1997): En contraste con la amplia participación masculina en proyectos, se encontraron colaboraciones femeninas relevantes en redacción, gráfica e investigación, además de entrevistas o artículos sobre mujeres que han destacado en roles referentes a arquitectura, urbanismo, patrimonio y teoría. Nombres locales recurrentes: Inés del Pino, Dora Arízaga, Olga Woolfson, Rocío Lagos, Patricia Fondello, Lucía Vásconez y Dolores Sánchez. Nombres extranjeros recurrentes: Evelia Peralta (Argentina) y Josefina Rebellón (Cuba). 


\begin{tabular}{|c|c|c|c|c|c|c|c|}
\hline $\begin{array}{c}\text { 1ra. mujer en } \\
\text { ingresar a una } \\
\text { carrera de } \\
\text { arquitectura. } \\
\text { Universidad } \\
\text { de Guayaquil. }\end{array}$ & $\begin{array}{c}\text { Llega a Ecuador } \\
\text { convirtiendose } \\
\text { en la lera mujer } \\
\text { en ejercer } \\
\text { arquitectura en } \\
\text { el país. }\end{array}$ & $\begin{array}{l}\text { 1ra. mujer } \\
\text { en obtener el } \\
\text { título de } \\
\text { arquitecta en } \\
\text { el ecuador. } \\
\text { UCentral. }\end{array}$ & $\begin{array}{c}\text { 1ra. docente } \\
\text { mujer } \\
\text { arquitecta de } \\
\text { la } \\
\text { Universidad } \\
\text { de Cuenca. }\end{array}$ & $\begin{array}{l}\text { 1ra.docente } \\
\text { mujer } \\
\text { arquitecta de } \\
\text { la } \\
\text { Universidad } \\
\text { Central. }\end{array}$ & $\begin{array}{c}\text { 1ra. docente } \\
\text { mujer } \\
\text { arquitecta de } \\
\text { la } \\
\text { Universidad } \\
\text { de Guayaquil. }\end{array}$ & $\begin{array}{l}\text { 1ra. mujer } \\
\text { jurado en la } \\
\text { Bienal de } \\
\text { Quito. }\end{array}$ & $\begin{array}{l}\text { 1ra. mujer } \\
\text { decana de } \\
\text { Facultad de } \\
\text { Arquitectura } \\
\text { en Ecuador. } \\
\text { UCSG. }\end{array}$ \\
\hline 1930 & 1956 & 1967 & 1970 & 1971 & 1972 & 1980 & 2008 \\
\hline $\begin{array}{l}\text { Otilia } \\
\text { Plaza } \\
\text { Ecuador }\end{array}$ & $\begin{array}{l}\text { Ethel } \\
\text { Arias } \\
\text { Uruguay }\end{array}$ & $\begin{array}{l}\text { Cecilia } \\
\text { Rosales } \\
\text { Colombia }\end{array}$ & $\begin{array}{l}\text { Lupe } \\
\text { Ibarra } \\
\text { Ecuador }\end{array}$ & $\begin{array}{l}\text { Mélida } \\
\text { Estrada } \\
\text { Ecuador }\end{array}$ & $\begin{array}{l}\text { Ángeles } \\
\text { Martín } \\
\text { Ecuador }\end{array}$ & $\begin{array}{l}\text { Betty } \\
\text { Fishman } \\
\text { Chile }\end{array}$ & $\begin{array}{c}\text { Rosa } \\
\text { Rada } \\
\text { Ecuador }\end{array}$ \\
\hline
\end{tabular}

Gráfico 1: Eventos relevantes.

Fuente: Autoras

\#PraTodoMundoVer Línea del tiempo que especifica año, personaje, nacionalidad y evento con la siguiente información: 1930, Otilia Plaza, Ecuador, Primera mujer en ingresar a una carrera de arquitectura. 1956, Ethel Arias Duarte, Uruguay, Primera mujer en ejercer arquitectura. 1967, Cecilia Rosales, Colombia, Primera mujer en obtener título de arquitecta UCE. 1970, Guadalupe Ibarra, Ecuador, Primera mujer docente UCUENCA. 1971, Mélida Estrada, Ecuador, Primera mujer docente UCE. 1972, Ángeles Martín González, Ecuador, Primera mujer docente UG. 1980, Betty Fishman, Chile, Primera mujer jurado Bienal Quito. 2008, Rosa Rada, Ecuador, Primera mujer decana de una facultad de arquitectura en Ecuador, UCSG.

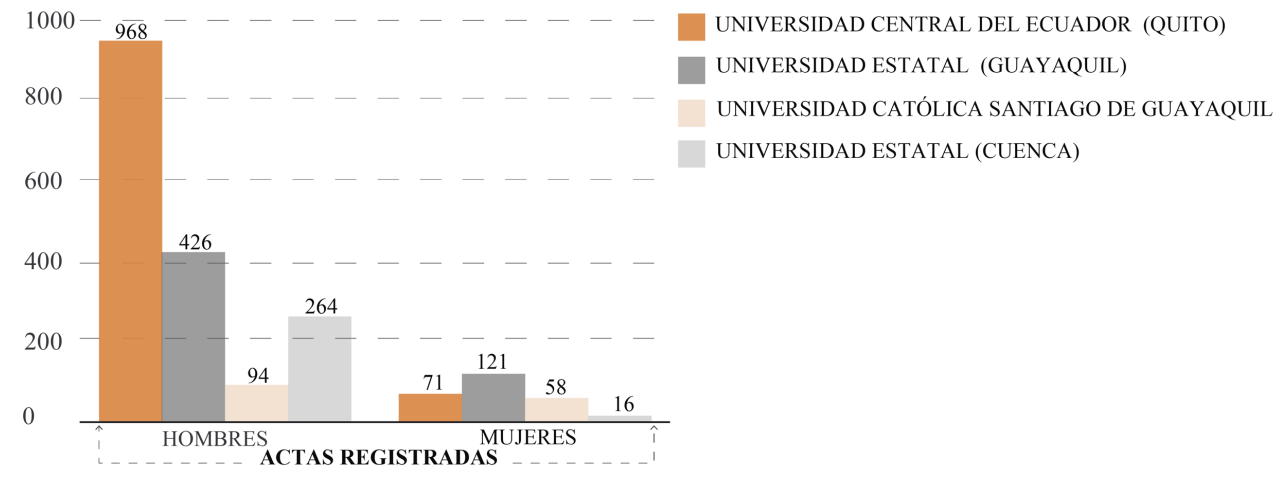

Gráfico 2: Resumen de graduados/as en universidades del Ecuador hasta 1980.

Fuente: Autoras

\#PraTodoMundoVer Gráfico de barras que contrasta cantidad de graduados por género en cuatro universidades. Datos: UCE, Quito, 968 hombres, 71 mujeres. UG, Guayaquil, 426 hombres, 121 mujeres. UCSG, Guayaquil, 94 hombres, 58 mujeres. UCUENCA, Cuenca, 264 hombres, 16 mujeres. Evidencia las disparidades con relación a la participación de graduados por género en cada universidad, que en el caso de las universidades de Quito y Cuenca muestra una participación femenina mucho menor (6 a 7\%) versus las universidades de Guayaquil, donde esta participación se incrementa (22 a 38\%).

Arquitectura y Sociedad (1975 a 1980): Revista adscrita a la FAU UCE como aporte a la divulgación teórica y crítica sobre la arquitectura. Evidencia escasa participación femenina; no obstante, se encuentran aportes de Patricia Abril, Noemy Flores, María Samaniego y Alexandra Moncada, pertenecientes a las generaciones posteriores a 1980.

\section{Guías Arquiltectónicas}

Guía de Arquitectura de Quito - Junta de Andalucía (2004): Editada por la Embajada de España, Agencia Española de Cooperación Internacional para el Desarrollo (AECID), Junta de Andalucía y Municipio de Quito, es un primer inventario de obras relevantes en la ciudad. Destaca la participación de arquitectas en grupos mixtos en campos de Restauración/Rehabilitación. Nombres recurrentes: Olga Woolfson, Inés del Pino, Patricia Fondello, Aura Arellano, Soledad Dulce, Esperanza Fonseca, Ruth Aguirre, Olga de Assaf, Gabriela Merino y Natalia Corral. En cuanto a edición e investigación existe una importante presencia femenina: Evelia Peralta, Alexandra Silva, Soledad Salazar, Natalia Corral y María Samaniego.

Guía de Arquitectura de Quito - Trama (2007): Editada por Trama, muestra obras de arquitectura y urbanismo relevantes. Se nombra a Ethel Arias, Olga Woolfson, Patricia Fondello, Soledad Dulce, Ana Viteri, Aura Arellano, Dolores Sánchez, Gabriela Merino, Marcela Alemán, Mariana Vaca, Dolores Montaño, Karina Borja, Inés del Pino, Alexandra Silva, María Gudiño, Carolina Almeida, Silvana Falconí, Silvana Sacón, Verónica Mora y Natalia Corral. En investigación/edición destacan: Evelia Peralta, Inés del Pino y Alexandra Silva. 
Guía de Arquitectura de Cuenca - Junta de Andalucía (2007): Esta guía es un catálogo de obras relevantes de arquitectura cuencana. Mediante cuatro itinerarios muestra la época colonial, republicana y del siglo XX. El libro no cuenta con obra alguna de la primera generación de arquitectas. Destaca Lourdes Abad con dos obras de restauración, Katty León y Mariana Sánchez como parte del grupo de investigación. Todas ellas pertenecen a la 2da y 3ra generación de arquitectas. (Gráfico 1)

\section{Memorias de las Bienales de Arquitectura de Quito (1978 a 1998)}

En 1962 se crea el Colegio de Arquitectos del Ecuador en Quito, entidad que instaura la Bienal de Arquitectura de Quito (1978) como oportunidad para reflexionar sobre y difundir la arquitectura local e internacional mediante eventos de confrontación, seminarios, exposiciones y conferencias. Estos eventos se resumen en memorias, que fueron analizadas entre 1978 y 1998 . En los inicios, la participación femenina era principalmente internacional. Desde la 4ta edición (1984) colaboran arquitectas ecuatorianas: Inés del Pino, Aura Arellano, Lucía Vásconez. En adelante, esta participación se incrementará, con Olga Woolfson, Dora Arízaga, Karina Borja, Dolores Sánchez, Alexandra Silva, entre otras. En cuanto a premios, la primera mujer ecuatoriana con este reconocimiento es Dora Arízaga, que junto a Evelia Peralta y otros colegas, obtuvo en 1992 el primer premio nacional en la categoría Teoría, Historia y Crítica de la Arquitectura.

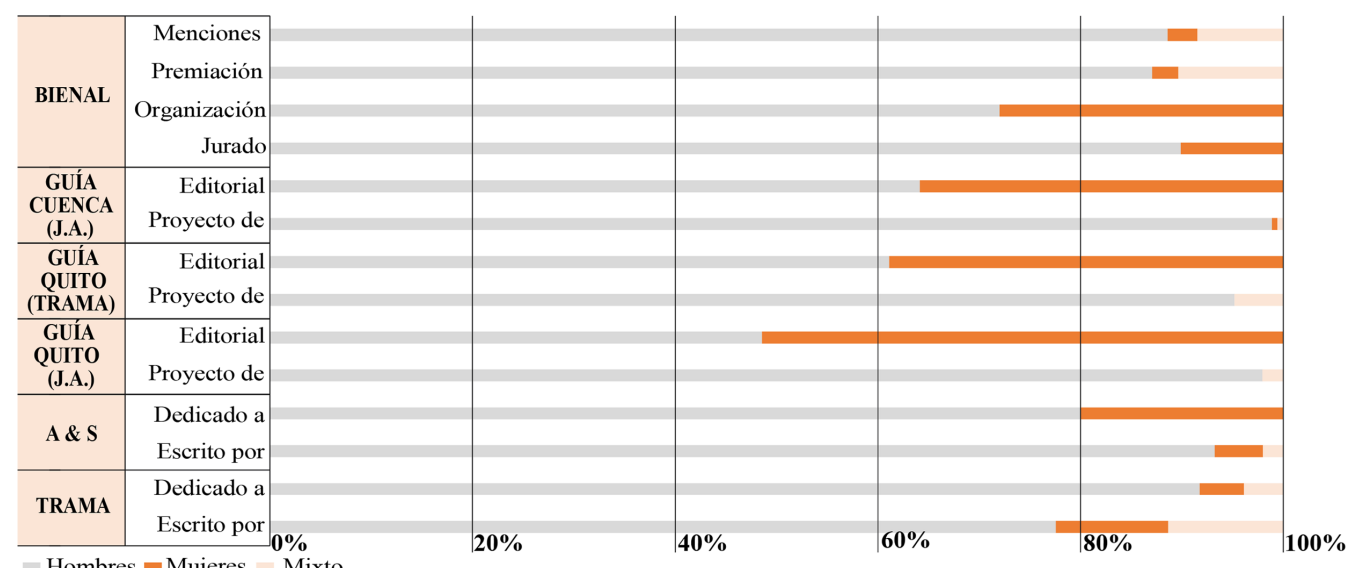

Gráfico 3: Aportes revistas locales, Guías de Arquitectura y Bienal de Arquitectura de Quito.

Fuente: Autoras

\#PraTodoMundoVer Gráfico con barras horizontales que indica participación por género. Publicaciones: Trama: 546 hombres, 78 mujeres y 80 grupos mixtos. Arquitectura y Sociedad: 138 hombres, siete mujeres y tres grupos mixtos. Artículos dedicados a: Trama a 855 hombres, 41 mujeres y 36 grupos mixtos y Arquitectura y Sociedad cuatro hombres, una mujer. Guías de arquitectura. Quito - Junta Andalucía: 570 proyectos de hombres, y 12 grupos mixtos. Equipo editorial: 17 hombres y 18 mujeres. Guía Quito - Trama: 634 proyectos de hombres y 32 grupos mixtos. Equipo editorial: 11 hombres, siete mujeres. Cuenca - Junta de Andalucía: 175 proyectos de hombres, una mujer y un grupo mixto. En equipo editorial: 34 hombres y 19 mujeres. Organizadores y ganadores en Bienal. Jurado: 240 hombres y 27 mujeres. Organización: 378 hombres, y 147 mujeres. Premios a: 101 hombres, tres mujeres y 12 grupos mixtos. Menciones a: 241 hombres, ocho mujeres y 23 grupos mixtos.

\section{Las pioneras de la arquitectura ecuatoriana. Perfiles relevantes}

Tras la revisión de la presencia de perfiles en medios especializados, actas de grado y trabajos de titulación de las primeras Facultades, se detectaron algunos perfiles relevantes. En su mayoría accedimos a ellas para entrevistarlas y complementar la información cuantitativa con información cualitativa. Los perfiles se detallan con relación a cuatro campos: Proyecto y Construcción, Academia y Vocación Teórica, Urbanismo y Sociedad, y Patrimonio y Rehabilitación.

\section{Proyecto y construcción}

Ethel Arias Duarte (Tacuarembó, Uruguay, 1925-2015)

Se titula en 1953 en la Universidad de la República de Uruguay (UDELAR). Su perfil tiene especial importancia ya que fue, según los registros revisados, la primera mujer en homologar su título en la UCE en 1956 y ejercer la arquitectura en este país: "Ethel Arias de León, joven arquitecta uruguaya, primera mujer en el país en esta profesión." (Andrés PEÑAHERRERA, 1996). 

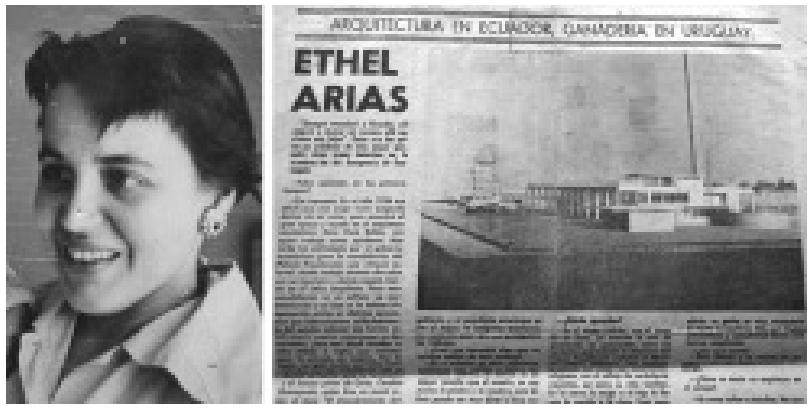

Imagen 2: Arias, foto 1950 y Recorte del Diario La Mañana, Uruguay, 1977.

Fuente: Cortesía de Mónica León Arias \#PraTodoMundoVer Foto de Ethel Arias en su juventud y recorte de periódico con el titular "Arquitectura en Ecuador y Ganadería en Uruguay" y una fotografía del Aeropuerto de Guayaquil, edificio moderno de color blanco.

Mientras la presencia de arquitectos uruguayos en Ecuador es ampliamente conocida, el trabajo de Arias es desconocido. Llega a Ecuador en 1954, año que coincide con la nominación de Ecuador como sede de la XI Conferencia Interamericana de Cancilleres. Su viaje se debe a la relación entablada con el arquitecto ecuatoriano Alfredo León, mientras él cursaba su posgrado en la UDELAR. Debido a la relación previa entre León y Sixto Durán Ballén (en aquel momento Ministro de Obras Públicas), se vinculan inmediatamente al privilegiado grupo de su firma, ARQUíN. La Conferencia, aunque no ocurrió, promovió varios proyectos emblemáticos, entre ellos, la remodelación integral del Palacio de Gobierno. La revisión de varios documentos corrobora su participación como ejecutora principal del proyecto: "Visitando el estudio del pintor ecuatoriano Oswaldo Guayasamín quien tiene a su cargo la construcción de un mural en la parte central del Palacio Nacional, (...). Los acompaña la Arquitecta Ethel Arias de León a cuyo cargo está la obra de la reconstrucción del Palacio." (El Comercio, 1959). "(E)n la década de los '50, el Arq. Sixto Durán Ballén (...) contrató a la arquitecta uruguaya Ethel Arias, para la remodelación integral del Palacio Presidencial, obra de gran magnitud y significación." (PERALTA, 2016, p. 85). Durán Ballén confirma: "Carondelet no me era extraño, pues el presidente Ponce Enríquez me había pedido, en 1956, que coordinara la planificación y las posteriores obras de restauración (...). De inmediato se organizó un Departamento de Planificación, bajo la dirección de la arquitecta Ethel Arias de León" (DURÁN BALLÉN, 2005, p. 43). En el diario uruguayo La Mañana, Arias también explica:

[F]ui contratada por el gobierno ecuatoriano para la remodelación del Palacio Presidencial, una reliquia colonial, donde trabajé durante dos años con un ingeniero y demás equipo, siendo yo el único arquitecto. Para esta remodelación en un edificio ya muy deteriorado y al cual se le habían ido agregando partes en distintas épocas, tuve que interiorizarme cuidadosamente del estudio colonial. (La Mañana, 1977)

El mismo artículo menciona otras obras ejecutadas tras la solvencia demostrada: en Quito, la restauración del hall del Correo Central, y planos, reformas y obras de mantenimiento para el Ministerio de Obras Públicas y Comunicaciones. En Guayaquil fiscalizó la construcción del aeropuerto y reformó el vestíbulo de Telecomunicaciones. Su última obra, aunque no construida, fue el diseño de un hotel en Otavalo. La participación de Arias en Ecuador abrió un camino a una generación de mujeres que en aquellos años empezaban a plantearse una formación universitaria en arquitectura y constituye un referente de empoderamiento en una época en la que el ejercicio de esta profesión aún no se abría para las mujeres.

\section{Guadalupe Ibarra Vásconez (Quito, Ecuador, 1947)}

Nacida en Quito, viaja a Cuenca en su adolescencia. Allí decide estudiar arquitectura, titulándose en 1970 en la UCUENCA, convirtiéndose en la primera mujer ecuatoriana titulada en arquitectura en el país, junto a sus colegas guayaquileñas. Inmediatamente concursa por una plaza en docencia en la misma universidad, obteniendo la calificación más alta. Dictó las materias de Taller, Dibujo Técnico y Materiales de Construcción.
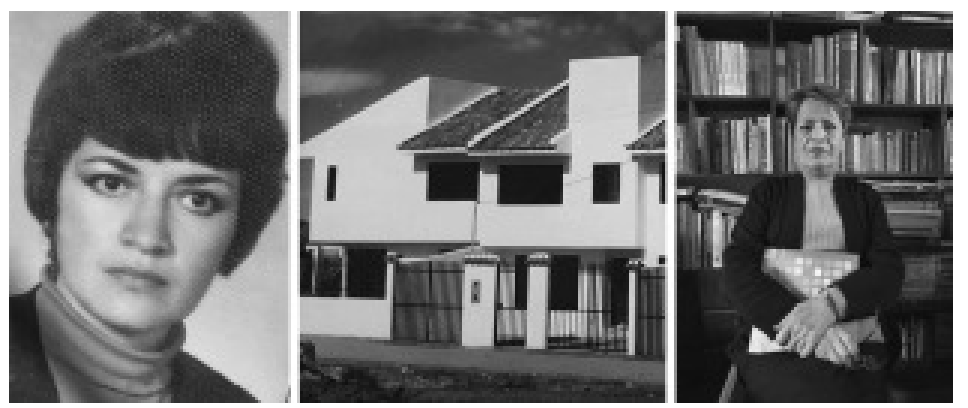

Imagen 3: Ibarra, años de juventud y actualidad/ Viviendas Calle Lope de Vega.

Fuente: Archivo personal Guadalupe Ibarra

\#PraTodoMundoVer En los extremos, fotos de Guadalupe Ibarra en su juventud y en la actualidad. En el centro, foto de "Condominio San Sebastián", proyecto de viviendas multifamiliares de dos pisos, blancas y con techo inclinado. 
Ejerció la docencia hasta 1978; posteriormente se enfocó casi de manera exclusiva a la planificación y construcción. En sus cinco décadas de ejercicio profesional planificó 220 viviendas, 13 conjuntos habitacionales, varios condominios y edificios de viviendas. Entre ellos: Hogar Infantil \#4, Casa de Observación Femenina "Florencia Astudillo", Capilla de las Madres de la Asunción, Convento de las Madres Salesianas de Gualaceo, Capilla para la Comunidad de Gapal. Su obra es heterogénea, pero ligada a la tradición cuencana. Varios proyectos fueron encargados por entidades públicas, como la Empresa Eléctrica Regional Sur o la Junta Nacional de la Vivienda.

Pese a su prolífica trayectoria, no hay prácticamente registro de su obra. Fue gracias un artículo publicado en EI Tiempo que se conoce someramente sobre su perfil. "Sus obras son innumerables, siendo la última el conjunto residencial de Racar, con 95 viviendas." (El Tiempo, 2008). Durante un corto periodo fue coordinadora del Ministerio de Bienestar Social en Cuenca, pero su preferencia por la construcción la llevó a una dedicación intensiva en este aspecto. En 2004 aprendió un sistema (adquirido por la Mutualista Azuay) a base de formaletas con moldes para construir en hormigón armado. Tras esta experiencia, realizó sus propios moldes en madera para ejecutar esta técnica independientemente en el proyecto con el que finalizó su carrera: el Condominio San Sebastián, a su criterio, su obra más importante por su carácter experimental. Su trayectoria le hizo merecedora de una mención especial de la Cámara de la Construcción de Cuenca. Al entrevistar a Ibarra, es evidente su amplia experiencia en construcción, adquirido empíricamente a través de la práctica, desafiando las preconcepciones, no sólo de la época en que desarrolló sus estudios, sino también las actuales. Es una mujer a pie de obra, quien asegura haber tenido una cordial relación con obreros y colegas. La clave: el apoyo de sus padres y de su pareja (de profesión abogado, quien aprendió de ella la supervisión de obra) y, especialmente, su empoderado carácter de cara al oficio.

\section{La academia y la vocación teórica}

Evelia Peralta (Tucumán, Argentina, 1941)

Se titula en la Universidad Nacional de Tucumán (1967). Allí se desempeñó como ayudante de docencia en Historia y luego como docente del 'Taller Total' que la vinculó con movimientos universitarios argentinos, cuyos fines eran la búsqueda de mejores condiciones para la universidad y la arquitectura. Esto provocó una persecución por parte de la dictadura, obligando a Peralta y su familia a emigrar a Ecuador en 1975.
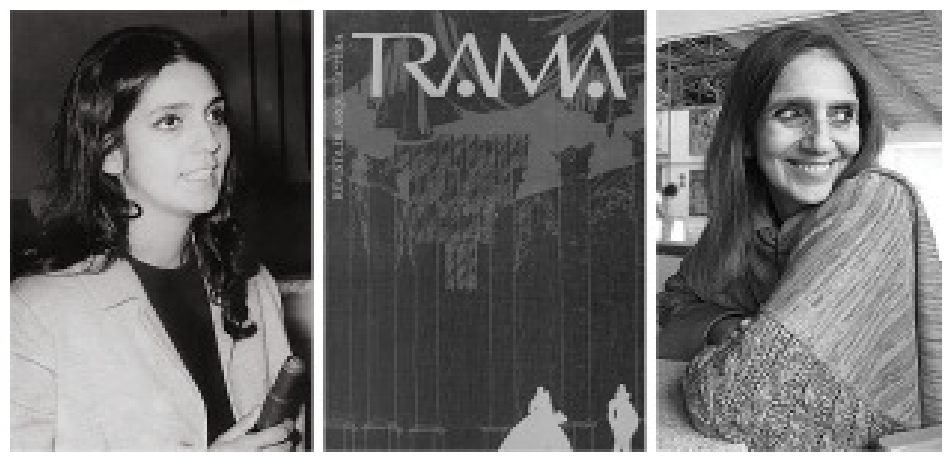

Imagen 4: Peralta, años de juventud y actualidad/ portada Revista TRAMA

Fuente: Archivo personal de Evelia Peralta \#PraTodoMundoVer En los extremos, fotos de Evelia Peralta de joven y en la actualidad. En el centro, portada de la Revista TRAMA, fundada en 1977, que muestra unas siluetas de personas sobre un fondo con boceto.

En reciprocidad por la acogida, se planteó como misión 'entregar' un aporte al país. Así surge la revista Trama (1977), que reconoce y valora proyectos arquitectónicos de varios periodos, reflejando diversas corrientes locales. Evelia colabora desde entonces como editora de libros, investigadora y escritora de artículos, en lo que actualmente es una editorial de trascendencia latinoamericana. Su objetivo, afirma, fue dar espacio a profesionales interesados en reflexionar, priorizando la idea de poner en valor lo que está bien, lo que construye. (PERALTA, 2018). Uno de sus aportes fundamentales fue su colaboración la edición de Guías de Arquitectura de Quito.

Desde su llegada se incorporó como docente en la FAU UCE en las asignaturas Teoría, Historia y Taller. Representó a la UCE en la Conferencia Latinoamericana de Escuelas y Facultades de Arquitectura (CLEFA) realizada en Guayaquil (1978) con el 'Taller Integral', donde explica su metodología, aplicando conocimientos previos del 'Taller Total'. Su participación abogó por transversalizar el conocimiento y entender la arquitectura no como reproducción de lo existente sino como crítica, resaltando la importancia de la teoría como reflexión del proyecto. Fue una de las fundadoras de la Bienal de Arquitectura de Quito, colaborando como organizadora en sus primeras ediciones y una de las primeras mujeres en recibir un premio por sus investigaciones: 3ra Bienal (1982) 1er Premio, Categoría Revistas, junto a Rolando Moya, y 8va. Bienal (1992) 1er. Premio Nacional, Categoría Teoría, Historia y Crítica de la Arquitectura, junto a varios autores. En el campo de la rehabilitación realizó el proyecto para el Centro Cultural Mama Cuchara junto a Dolores Montaño, Karina Borja, y otros colaboradores. 
En 1994 se integra a la Facultad de Arquitectura, Diseño y Artes de la Pontificia Universidad Católica del Ecuador (PUCE) donde continúa su actividad docente. Evelia, pese a no ser ecuatoriana, es un perfil relevante en el panorama local por ser pionera en la promoción de la arquitectura ecuatoriana desde la reflexión crítica frente a la historia y la actualidad.

Inés Del Pino (Quito, Ecuador, 1955)

Se titula en 1980 en la UCE del Ecuador. Durante sus estudios, destacó en las asignaturas Construcción y Teoría, donde despertó su interés por la arquitectura prehispánica del Ecuador, inspirada en piezas arqueológicas encontradas en el Museo del Banco Central. Esto derivó en su trabajo de titulación "Tipologías Arquitectónicas Precolombinas" realizado junto a Mercedes Ruiz y Elisa Toledo (1980), y posteriormente publicado por el Colegio de Arquitectos (1981).
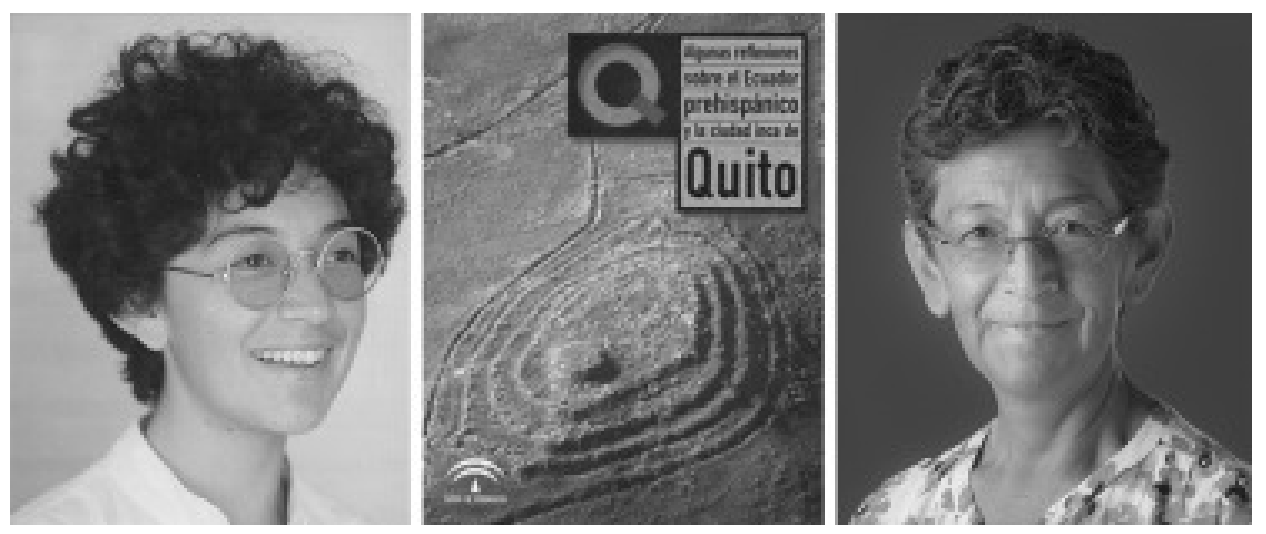

Imagen 5: Del Pino, años de juventud y actualidad, y portada de libro.

Fuente: Archivo personal de Inés del Pino y Centro de Publicaciones PUCE.

\#PraTodoMundoVer En los extremos, fotos de Inés del Pino de joven y en la actualidad. En el centro, portada de libro "Algunas reflexiones sobre el Ecuador prehispánico y la ciudad inca de Quito" que muestra una fotografía aérea de ruinas precolombinas.

Además, trabajó en el Centro de Matemática de la UCE, lo que le permitió obtener una beca en Versalles, Francia, para cursar Procesamiento automatizado de la información con aplicación a proyectos (1978). Posterior a su graduación colabora como redactora en Trama y Serie Quito del Municipio de Quito en colaboración con la Junta de Andalucía. En 1982 recibe una beca para estudiar conservación arquitectónica en el Centro de Restauración de Roma (ICCROM). Luego participó en el proyecto de restauración del Antiguo Edificio del Banco Central, obra que definió su interés por los aportes de los arquitectos italianos en la producción local, derivando en la publicación de un libro junto a Florencio Compte. Fue Subdirectora Nacional de Patrimonio Cultural del Ecuador (1988), siendo la primera mujer en alcanzar ese cargo. Al año siguiente, en Madrid, trabaja en la Sociedad Estatal 5to Centenario del AECID, donde realizó el seguimiento y evaluación de proyectos de restauración y rehabilitación en Latinoamérica. En 1992 colabora con AECID en Ecuador, para dirigir la Escuela Taller Quito II, un proyecto de formación de artesanos de la construcción y rehabilitación arquitectónica. Colaboró en proyectos editoriales y estudios auspiciados por la Junta de Andalucía hasta el 2004.

Desde 2000 hasta la actualidad, Inés ejerce la docencia en la PUCE donde inicia su investigación sobre Arquitectura Moderna, que derivó en el libro Quito, 30 años de Arquitectura Moderna.1950-1980. En adelante, dedica su labor a la producción de artículos, libros, apoyo a consultorías y proyectos de gestión cultural, enfocados a estudios patrimoniales e históricos.

En 2006 obtuvo el título de Máster en Estudios de la Cultura y más adelante el de Máster en Gobierno de la Ciudad, estudios que le permitieron profundizar sobre el pensamiento latinoamericano y la gestión del patrimonio. En 2017, finalizó su doctorado con la tesis Espacio urbano en la Historia de Quito: Territorio, traza y espacios ciudadanos, trabajo que representó el colofón de los temas tratados en su carrera profesional. La amplia producción de Del Pino aporta al conocimiento de la historia urbana y arquitectónica ecuatoriana. Su trayectoria da cuenta de su importancia como referente de la Teoría e Historia Arquitectónica Latinoamericana.

\section{Urbanismo y sociedad}

Ana Solano de la Sala (Guayaquil, Ecuador, 1948)

Se titula en 1974 en la UCSG con el trabajo: La vivienda como problema estructural y la ciudad en sus aspectos históricos, político, económico, social y físico. Motivada por los problemas urbanos de su ciudad, obtuvo en 1977 en Francia su Máster en Urbanismo. Esta experiencia cambió su visión hacia una ideología progresista, ya que fue una de las primeras arquitectas 
guayaquileñas en estudiar un postgrado, situación que provocó rechazo por parte de los miembros de su universidad.
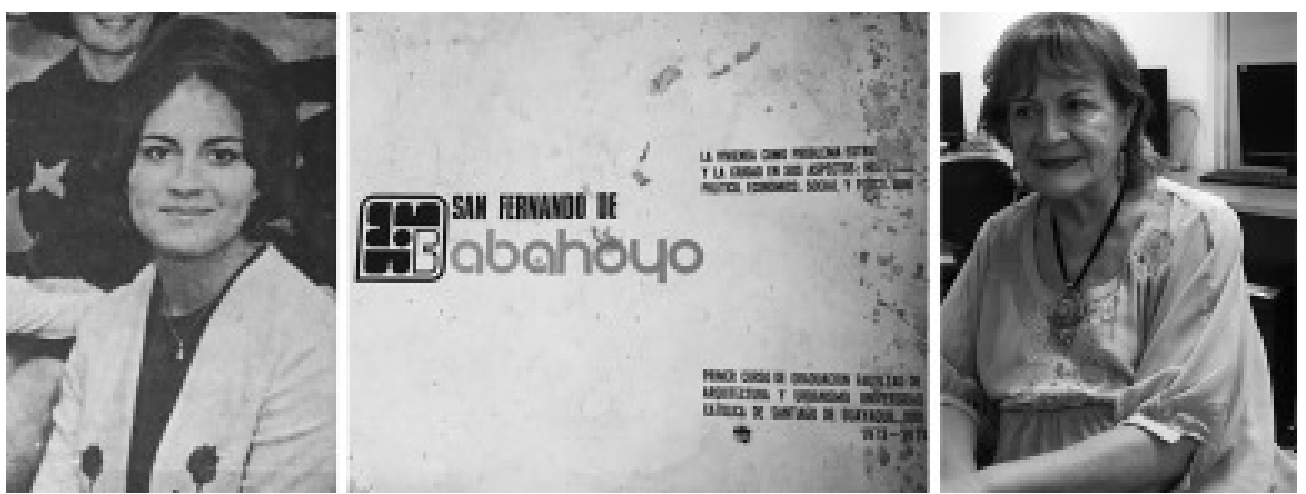

Imagen 6: Solano, años de juventud y actualidad, y portada de su trabajo de titulación. Fuente: Archivo personal de Ana Solano.

\#PraTodoMundoVer En los extremos, foto de Ana Solano de joven y en la actualidad. En el centro, portada de su trabajo de tesis de grado localizada en San Fernando de Babahoyo, Ecuador. No muestra imágenes, únicamente el título del trabajo.

Dedicó su vida a la academia como profesora de diseño urbano en la UG (10 años) y en la UCSG (33 años). De carácter multifacético, emprendió trabajos de diversa índole que le permitieron abarcar diversas áreas relacionadas a asentamientos humanos sostenibles, organización territorial y planificación urbana, y diseño arquitectónico naval y edificaciones náuticas. Posee una gran variedad de cursos y diplomados, entre ellos, uno en el Instituto de Urbanismo de Paris Val de Marne. Fue directora del Instituto de Investigación Urbana de la UCSG, y participó junto con la Universidad de Lund, Suecia, en el programa PROMESHA, relativo a la vivienda. Tuvo una importante participación en la planificación de Guayaquil en calidad de directora del Plan de Áreas Verdes. Actualmente, ya jubilada, continúa su labor académica en la UCSG como profesora Ad Honorem, como investigadora en urbanismo y materiales alternativos.

\section{Marcela Blacio (Guayaquil, Ecuador, 1950)}

Se tituló en la UG en 1978. Su vocación hacia la docencia la llevó a estudiar también Educación Media con Especialización en Supervisión y Administración Educativa (Universidad Técnica Particular de Loja, 1997). Cuenta con un Máster en Antropología del Desarrollo (Universidad del Azuay, 1992), que le permitió comprender la sociedad y la cultura. Obtuvo el Doctorado en Urbanismo (Universidad de Buenos Aires, 2019) con la tesis Espacio Público y relaciones de poder: el caso de Malecón 2000. Tiene en proceso un Doctorado en Antropología Social en la Universidad Nacional de San Martín.
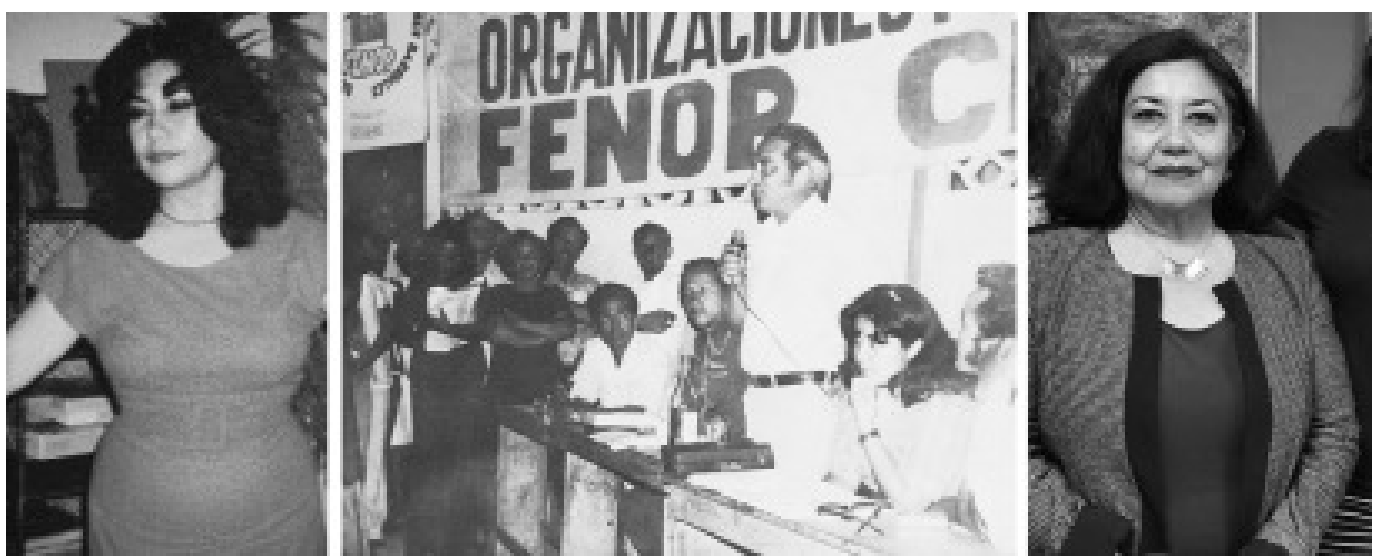

Imagen 7: Blacio, años de juventud, actualidad y participación en organizaciones civiles. Fuente: Archivo personal de Marcela Blacio y foto de las autoras.

\#PraTodoMundoVer En los extremos, fotos de Marcela Blacio de joven y en la actualidad. En el centro, foto de Marcela en una mesa dirigiendo el diálogo junto a un grupo de personas, miembros de la FENOP (organización social).

Su trayectoria en docencia universitaria se inicia en 1980 en la UG, vinculada al área de Urbanismo en pregrado y posgrado, colaborando también con la Facultad de Psicología y el Instituto de Diplomacia. Ha cumplido varias funciones directivas, entre ellas: Dirección del Instituto 
de Postgrado de la Facultad de Arquitectura (2005-2007), Dirección Académica de la Maestría Tecnologías Constructivas para Viviendas de Bajo Costo (2004 -2006), Dirección de la Oficina de Proyectos de Investigación (2003-2004), entre otros cargos, siendo su última designación la de Decana de la Facultad de Arquitectura y Urbanismo (2018-2019).

Su perfil de activista política la vinculó a la "Planificación con Participación Popular", participando en los Foros Montubios y Ciudadanos por la nueva constituyente (2007) y Fortalecimiento de Redes Ciudadanas: Agenda para el Desarrollo de la Subregión Colonche y Manglaralto (2006). Fue facilitadora en el Diálogo Nacional por la Unidad y el Desarrollo, Capítulo Guayas, para la Secretaría de Diálogo Social y Planificación (2003), entre otras actividades de sistematización, programación, asesoría técnica, monitoreo y evaluación de proyectos de desarrollo local, varios de ellos vinculados al Ministerio del Litoral. Destaca como consultora en temas de riesgos, cultura y antropología; como ejemplo, su coordinación técnico-administrativa del proyecto para el fortalecimiento del sistema de reducción de riesgos para el PNUD/SNGR (2012-2013). Ha participado en un centenar de eventos académicos en diversas universidades a nivel nacional e internacional. Entre sus publicaciones destacan: "Vivienda y universidad: lógicas sociales y familiares, escenarios y coreografía de relaciones humanas" (Revista AUC, 2008) y "Lo público y lo privado en el espacio público del Malecón Simón Bolívar: relaciones de poder y ciudadanía" (Revista Daya, 2018).

Blacio destaca por su enfoque en el campo de la participación popular, gestión del riesgo y capacitación comunitaria, como promotora social, y como educadora popular en sectores urbano-marginales de Guayaquil. Desde una visión de género, ha coordinado talleres y encuentros para organizaciones de mujeres gubernamentales y no gubernamentales, siendo gestora de la elaboración de diversos programas de formación continua.

\section{Patrimonio y restauración}

Olga Woolfson Touma (Quito, Ecuador, 1951)

Se tituló en 1980 en la UCE con el trabajo Puesta en valor de un Sector Histórico, que inspiró su especialización, motivada también por su participación en el Coloquio sobre Centros Históricos en Latinoamérica (1978). En 1983 se especializa en "Restauro dei Monumenti e dei Centri Storici" en Florencia, Italia. En 2019 se gradúa como Máster de Arqueología del Neotrópico en la Universidad Politécnica del Litoral.
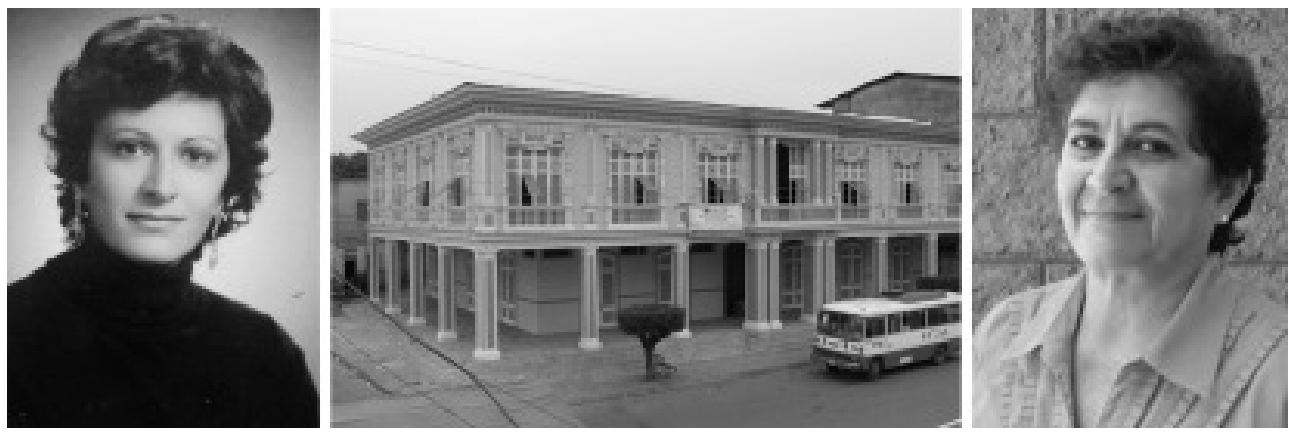

Imagen 8: Olga, años de juventud, actualidad y restauración del Palacio Municipal de Vinces. Fuente: Archivo personal Olga Woolfson y libro Decreto de Emergencia del Patrimonio Cultural.

\#PraTodoMundoVer En los extremos, fotos de Olga de joven y en la actualidad. En el centro, foto de obra de restauración del Palacio de Vinces, edificación esquinera de estilo neoclásico de dos pisos. En la planta baja tiene un porticado y en la planta alta ventanas con perfiles blancos.

Ocupó cargos relevantes en proyectos de restauración en Quito, destacando la Delimitación del Área Histórica para la preservación: Quito y su microrregión en el Plan de Quito (1980). Fue directora de restauración arquitectónica en el Museo del Banco Central del Ecuador. Fue coordinadora y directora del Fondo de Salvamento del Patrimonio de Quito (FONSAL), donde realizó varias restauraciones: Capilla de los Milagros (1990), Iglesia de Santa Bárbara (1992), Monasterio e Iglesia de San Juan (1993). (Alfonso ORTIZ, 2004, p. 66, 145, 172), recuperación del Núcleo Central e Imagen Urbana de Perucho (2005), Parque Arqueológico Rumipamba, Hospicio San Lázaro (antigua cárcel municipal). Realizó el expediente sobre áreas históricas para el Metro de Quito. En Guayaquil trabajó en el estudio patrimonial del barrio Las Peñas, reconstrucción del Banco Territorial del Parque Histórico, y remodelación del edificio del Museo Presley Norton. En 2008 fue nombrada directora del Proyecto del Decreto de Emergencia del Patrimonio Cultural del Ecuador, dedicado a la restauración de edificaciones patrimoniales en riesgo (Plan de Protección y Recuperación del Patrimonio Cultural del Ecuador, 2010).

Ha dictado alrededor de 40 conferencias y es autora de varias investigaciones sobre patrimonio arquitectónico y arqueológico, con una serie de artículos publicados en libros, revistas y periódicos nacionales e internacionales. Participó como coautora y editora de varios libros, entre 
ellos: Quito, Centro Histórico: Testimonios (1996), Especificaciones, detalles y documentos técnicos para intervención en patrimonio cultural inmueble y mueble (2000) y Decreto de Emergencia del Patrimonio Cultural. Un aporte inédito al rescate de nuestra identidad (2009). Woolfson, con una serie de importantes reconocimientos, es un referente en los estudios sobre patrimonio, con cerca de cuarenta años de experiencia.

\section{Dora Arízaga (Cuenca, Ecuador, 1952)}

Se titula en 1978 en la UCUENCA. Recibe una beca para el curso de Restauración de Monumentos Históricos en el Instituto Nacional de Cultura del Perú organizado por PNUD y UNESCO. Esto marcaría su vínculo con la arquitectura y el patrimonio ecuatoriano, influyendo en su trabajo de titulación: La recuperación del monasterio del Carmen de la Asunción de Cuenca, pionero en esta línea. Continuó sus estudios en las especializaciones "Restauro dei Monumenti" en Florencia, Italia y "Trabajos de Restauración Arquitectónica” en Madrid, España (1980-1981).
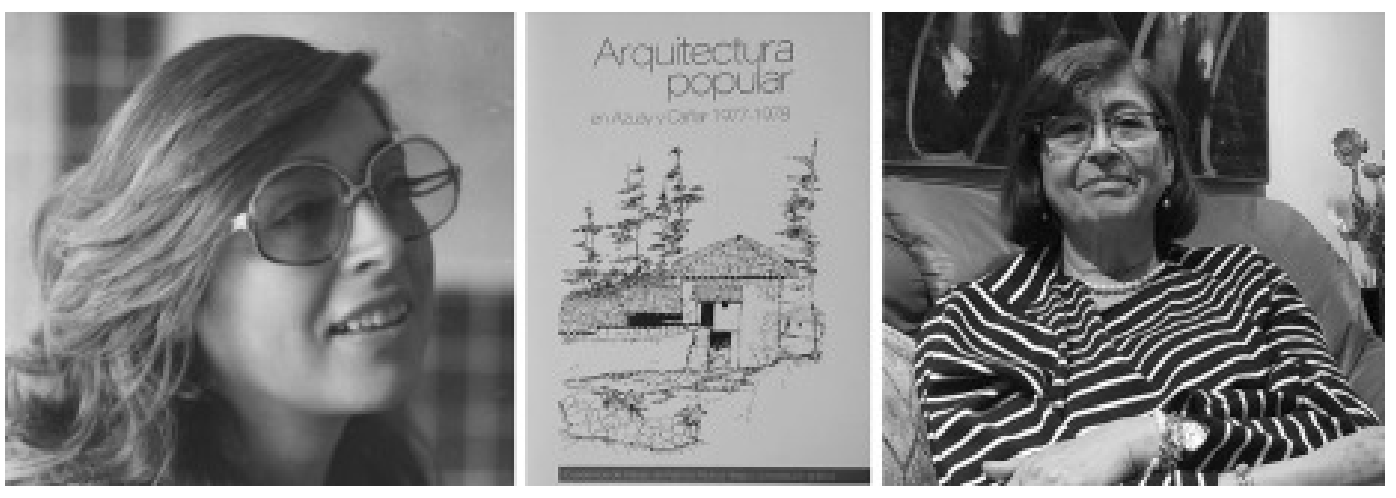

Imagen 9: Dora Arízaga, años de juventud, actualidad y portada del libro Arquitectura Popular. Fuente: Archivo personal Dora Arízaga y foto de las autoras.

\#PraTodoMundoVer En los extremos, fotos de Dora Arízaga de joven y en la actualidad. En el centro portada del libro: "Arquitectura popular en Azuay y Cañar", que muestra un boceto de una casa vernácula de la serranía ecuatoriana con árboles de fondo.

El arquitecto Patricio Muñoz la integró a su equipo para la investigación "Arquitectura popular en Azuay y Cañar", publicado como libro por el Centro Interamericano de Artesanías y Artes Populares (2016). Participó en Consulplan (1979) en el Plan de Desarrollo del área metropolitana de Cuenca con enfoque en el Centro Histórico. Dirigió el estudio Conservación del Centro Histórico de Cuenca y el Departamento de Investigaciones históricas, estéticas y arquitectónicas del Museo del Banco Central del Ecuador (1982). En 1988 fue parte del equipo fundador del FONSAL; allí trabajó hasta 1996, determinando políticas y objetivos para la conservación y recuperación del Patrimonio de Quito, ejecutando alrededor de 200 proyectos de restauración y desarrollo del Centro Histórico, que la convierten en un referente internacional en Patrimonio.

A raíz de ello, dictó varios cursos y seminarios en maestrías en Universidades de Brasil, Cuba, Argentina y España. En 2005 fue designada gerente administrativa del Banco Ecuatoriano de la Vivienda (BEV), donde organizó el banco de tierras para proyectos de vivienda social. Fue asesora en Patrimonio Cultural en el Ministerio de Cultura y Patrimonio (2008), en la formulación de planes y proyectos de patrimonio a nivel nacional. Conformó la Comisión Técnica de combate al tráfico ilícito de bienes culturales patrimoniales.

Es consultora para UNESCO sobre Patrimonio en Latinoamérica, desde 1989 hasta la actualidad. Fue docente de Historia en pregrado y en la maestría "Rehabilitación Urbano Arquitectónica" de la FAU-UCE, en la Universidad Andina Simón Bolívar de las maestrías: "Gestión y desarrollo del Patrimonio Cultural" y "Gestión de la Cultura" y en la Universidad de Cuenca de la maestría "Conservación de Monumentos y Sitios". Arízaga abrió un camino intelectual en el campo del Patrimonio Cultural en el Ecuador y Latinoamérica, mediante sus importantes aportes a esta temática en cuanto a gestión, planificación y proyecto.

\section{Discusión: igualdad vs. desigualdad. ¿Realidad o percepción?}

Las mujeres que se enfrentan al lugar que el patriarcado les tiene asignado emprenden una revuelta interior y exterior que necesariamente tiene que afectar a todo orden privado-doméstico, y llevarla a la práctica sin contradicciones no es fácil. (Ana DE MIGUEL, 1961, en Beatriz RANEA, 2019, p. 32)

El análisis presenta una evidente desproporción entre géneros. Sin embargo, al entrevistar a las arquitectas biografiadas observamos algunos discursos que niegan lo que las estadísticas muestran: la existencia de barreras de carácter estructural. Pese a que su legado profesional 
revela el espíritu progresista y actitud desafiante de mujeres que destacan en una profesión masculinizada, en un contexto conservador y patriarcal, algunas atribuyen la escasa presencia femenina a la falta de autoconfianza o esfuerzo, y no a una serie de estructuras sociales, políticas y gremiales que han limitado el acceso, la visibilidad y el ascenso profesional de la mujer.

Mónica León, hija de Ethel Arias, comenta: "Mucha gente era muy virulenta con ella, pero ella era más virulenta aún. Era una mujer de carácter fuerte, siempre a pie de obra" (Mónica LEÓN, 2018). Arias corroboraba la complejidad de su vinculación con el oficio: "En el año 1954 era difícil que una mujer fuera aceptada dentro de mi ramo, pero encontré el gran apoyo y ayuda en el arquitecto ecuatoriano Sixto Durán Ballén..." (La Mañana, 1977).

Dos décadas después de esta incursión, Guadalupe lbarra entra en el panorama. Asegura que siempre se sintió en igualdad de condiciones, aunque en sus inicios como estudiante debió ganarse la confianza de compañeros y profesores. "Fui la primera estudiante mujer en la facultad. Al comienzo tenía sólo compañeros hombres, el primer año fue un poco difícil, hasta que ellos se sintieron un poco en confianza conmigo. En esa época no era muy espontánea la relación entre hombres y mujeres" (EI Tiempo, 2008). Ibarra afirma que la maternidad fue su prioridad; esto implicó ciertas renuncias como no participar en concursos, no promover su trabajo, no continuar sus estudios y rechazar varias ofertas para incursionar en política. "Como mujeres tenemos un doble trabajo: el de ser madres y esposas, y además profesionales". Ibarra cree que "las mujeres tenemos una ventaja sobre los hombres, porque al diseñar una vivienda sabemos cómo funciona la casa" (IBARRA, 2019). Si bien lbarra comenta que su integración a la carrera fue natural y sin obstáculos, su testimonio corrobora roles preasignados a la mujer, evitando su ascenso y visibilidad, pues el género como constructo social ha estructurado la división entre trabajo remunerado 'productivo' y trabajo no remunerado 'reproductivo' siendo un factor no sólo de diferenciación político-económica sino cultural-valorativa (Nancy FRASER, 1947, en RANEA, 2019, p 42-43).

Ibarra manifiesta, quizá por incomprensión del término, que no quiere ser identificada como feminista. Esto se explica ya que el feminismo ha tenido un proceso lento de despolitización hasta trascender a la idea de que no importa la tendencia política, conservadora o liberal, para incorporarlo en el estilo de vida y filosofía personales. Aún queda trabajo para erradicar el descrédito que se ha atribuido al término y comprender que la igualdad que persigue el feminismo "no es enemiga de la diversidad ni de las diferencias (...) es un principio ético y político que rechaza la discriminación, la explotación, la exclusión, la subordinación y, en general, todas las opresiones." (Rosa COBO, en RANEA, 2019, p. 30).

Al preguntarle a Peralta sobre su percepción con respecto a las diferencias de género, ella opina:

Nunca busqué enfocarme en diferencias de género, sino en la integración, la complementariedad. Las mujeres son más ordenadas, aplicadas y siguen los pasos que se proponen, probablemente en las áreas de investigación histórica. (...) Los hombres tienen otra experiencia hacia los aspectos técnicos y quizá tienen más desarrollo en esa disciplina...las siguientes generaciones vienen con otras experiencias y otras ideas. (PERALTA, 2018)

Su comentario refuerza nuevamente los estereotipos y dificultades de las mujeres en la profesión. Del Pino también niega que la poca visibilidad de una mujer sea una cuestión estructural: "Hombres y mujeres somos iguales, el bloqueo a veces viene desde las mismas mujeres, y no porque el medio te impone... el medio quizá en ocasiones te impone, pero depende de uno, de la persona. Si tú misma te creas barreras, se reflejan en tu forma de ser y actuar." Preguntamos por qué entonces los perfiles detectados son prácticamente invisibles, a lo que responde: "No somos invisibles, simplemente no se habla de nosotras" (DEL PINO, 2019). En Guayaquil, preguntamos a Ana Solano: ¿hay segregación?, a lo que responde: "Cuando la mujer cree que está segregada es porque esa es una actitud interna de segregación, pero cuando una se siente capaz y segura de sí misma, jamás vas a sentir segregación." Estos dos testimonios muestran cómo la negación es un fenómeno/reacción habitual cuando se plantea el debate sobre desigualdades, ocasionado por una 'disonancia cognitiva' donde entran en conflicto creencias culturales arraigadas y el desafío a sistemas de ideas preestablecidas, tendiendo a creer que la desigualdad es casual y aleatoria, cuando "(p)or el contrario, se atiene a datos constantes.(...) Largos siglos sometidas a una socialización generalizada que se ha concretado socialmente en el ejercicio de roles" (COBO, 1956, en RANEA, 2019, p. 45). En la arquitectura estos roles se manifiestan de maneras específicas:

Hay pocas mujeres referentes en la profesión, mujeres con las que identificarse, sobre todo en relación con la masa que está trabajando. Las mujeres ganan menos concursos, son menos publicadas, son minoritarias en órganos de representación colegial y en puestos importantes, dentro de las Escuelas ocupan un segundo plano, y las que son visibles y/o conocidas lo son muchas veces a partir de asumir un modelo ya establecido (masculino) y tienen una imagen algo negativa (son vistas desde la renuncia(...).). (Patricia MOLINA; Begoña LAQUIDÁIN, 2009, p. 56)

En el caso de Guayaquil, la profesión tuvo un enfoque más liberal, es así como Solano afirma: 
En Guayaquil hay un despertar de la mujer hacia profesionalizarse, tiene que trabajar porque hay una demanda que exige la época. La arquitectura va acompañada con esa sensibilidad de la creatividad y eso hace que las mujeres nos encasillemos más hacia ese lado, pero tenemos la capacidad de hacer trabajos fuertes como la construcción. (SOLANO, 2019)

Dora Arízaga es uno de los pocos perfiles sin temor a ser identificada como feminista; explica que elegir esta profesión era un desafío para la sociedad y la familia: "la arquitectura es una profesión para hombres y se debe buscar algo más adecuado para una mujer" decía su padre para persuadirla de no estudiar esta carrera. Dora resalta la dificultad que representaba para una mujer estudiar arquitectura y ejercerla, siendo necesario un mayor esfuerzo académico y profesional para destacar (ARÍZAGA, 2019). Los datos evidencian no solo las dificultades de las mujeres para incursionar en la arquitectura, sino una serie de roles, destinándolas a áreas menos tecnificadas y visibles. Marcela Blacio explica el fenómeno de por qué hay una negación sobre la evidente desigualdad:

La hegemonía política no les permite aceptar, tienen miedo de reconocerse como transgresoras de las formas de vida tradicionales de la sociedad y han tenido que afrontar cosas y anécdotas que no quieren aceptar. Cuando eres diferente tienes confrontaciones, pero debes tener claro lo que eres. (...) El feminismo es una liberación, el hecho de ser diferente y actuar diferente. Sabemos que nos van a criticar, pero nos da la posibilidad de crecer. (BLACIO, 2019)

\section{Conclusiones}

Dificultades - Esta investigación se construyó pese a una serie de dificultades que deben ser subsanadas en futuras indagaciones. El primer obstáculo fue la dispersión, desorganización, destrucción y escasez de documentación relacionada, de manera que los testimonios vivos, información que, pese a ser a veces imprecisa, fue la única fuente posible, recurriendo a redes de amistades, familiares, profesionales y académicas. Así, la probabilidad de que a futuro salgan a flote perfiles adicionales es alta. En definitiva, este documento no representa una 'última palabra', sino que incentiva a activar redes e indagar archivos personales e institucionales, para evitar nuevas pérdidas (como fue el caso de Ethel Arias: tras su fallecimiento se perdió mucha información) y consolidar fuentes de información que validen los aportes de la primera generación de arquitectas en el Ecuador.

Los datos hablan - La escueta información y difícil localización de mujeres en ejercicio profesional son evidencia de la desproporción entre géneros y las dificultades de las arquitectas para insertarse en el mundo laboral. Porcentajes mínimos de mujeres en los datos globales no son un asunto superficial: no es casual la asignación diferencial de roles profesionales, problemas de invisibilidad, sobreesfuerzo, promoción desigual hacia cargos de relevancia. La negación de la diferencia es otro arraigado obstáculo para alcanzar igualdad de condiciones y reconocimiento laboral. La conciencia sobre ello tendrá incidencia en las nuevas generaciones, que pese a contar con un ingreso prácticamente paritario en las aulas, no garantiza mayor presencia en el ejercicio profesional. Como ejemplo, un estudio realizado en España entre 2008 y 2014 evidenció que "a pesar del alto número de graduadas sólo un pequeño porcentaje ha seguido ejerciendo su profesión, la mayoría de las veces en situación precaria" (Nuria ÁLVAREZ, 2017, p.72).

La necesidad de visibilizar - Se observó en las entrevistas que, en su mayoría, cuando se trata de la ambición profesional interesa menos el éxito y más la satisfacción personal. No buscan poder, ni destacar por ser mujeres, ni confrontación, buscan hacer las cosas bien, ser buenas en su trabajo y trabajar en equipo, sin diferenciar el género. No se ven como víctimas, se sienten en igualdad de condiciones para ejercer esta profesión. No obstante, a pesar del talento y reconocimiento en un pequeño círculo, son prácticamente desconocidas en esferas más amplias, mientras 'los pioneros' son objeto de estudio y parte del imaginario local. Aunque la visibilización no es de su interés personal, a las autoras nos interesa como discurso: para las mujeres que ejercen actualmente la profesión, para las y los estudiantes que necesitan nuevos referentes y material bibliográfico, y, por supuesto, para la sociedad local que requiere completar su historia.

Pioneras y pensadoras - La visibilización de las pioneras va más allá del reconocimiento: requiere la reivindicación del pensamiento como una categoría tan importante como el diseño. Esto significa transitar de una cultura material a una intelectual, que tiene otros tiempos y otro proceso de desarrollo. Para ello, se requieren nuevos códigos de asimilación y nuevas escalas de valores de lo que es bueno y reseñable: "si son los valores y las experiencias de los hombres, a través del sistema patriarcal, los que establecen, entonces la mitad de la humanidad no cuenta, no hay lugar para otros valores ni experiencias ni saberes." (Inés MOISSET, 2017, p. 22). He aquí la importancia de la mirada a la historia de la arquitectura local desde una perspectiva feminista, donde descubrimos que las pioneras son en su mayoría pensadoras, por sus aportes que se encuentran esencialmente en la teoría y la historia de la arquitectura.

Slow vs. fast acknowledgment - En la actualidad, y en favor del reconocimiento de la labor de mujer, las nuevas generaciones han empezado a validar sus perfiles a través de redes sociales, 
si bien con interesantes perspectivas, pero con aportes aún incipientes. Estamos ante un fenómeno de fast acknowledgment (en analogía al término fast food) donde engordamos las referencias en base al minuto de fama, tornándose ésto más importante que la consolidación lenta y progresiva. Para las pioneras han pasado alrededor de cuatro décadas para que sean reconocidas como tales. Sin ningún afán mediático, estas mujeres nacidas en su mayoría entre 1940-1950 han trabajado sostenidamente, otorgando aportes en firme para las nuevas generaciones. El slow acknowledgment aboga por la responsabilidad sobre el conocimiento historiográfico y el trabajo prolongado y conciso. Previo a designar a representantes de la arquitectura local conviene mirar al pasado.

El germen de 1970 y el despertar actual - A nivel internacional, esta década se caracterizó por una serie de revueltas de reivindicación; entre ellas, la segunda ola del feminismo. Esta coyuntura llegaría escuetamente a un país conservador como Ecuador. Marcela Blacio, en su espíritu activista, es la única que hace alusión al germen de una década inspirada en la búsqueda de una nueva cultura alternativa a la hetero-patriarcal. Este pensamiento alternativo que caló tan solo en pequeñas esferas académicas y en ciertos discursos teórico-críticos, reaviva la llama de la búsqueda de esta nueva cultura al terminar la segunda década del siglo XXI con la cuarta ola de feminismo.

"Aunque quede mucho, muchísimo por hacer (y a veces nos dé la sensación de que está todo por hacer), estamos lejos del lugar de partida de aquellas pioneras que se movilizaron, y que transgredieron normas sociales para poder estar en los espacios en los que estamos." (RANEA, 2019, p 15-16)

Las autoras aspiramos a través de este documento alentar a un debate que tenga incidencia en el espacio de la producción material e intelectual de la profesión.

\section{Referencias}

ÁLVAREZ, Nuria. "La mujer arquitecta como sujeto de una necesaria redefinición de la práctica profesional desde la perspectiva española". De-arq (Universidad de los Andes), n. 20, p. 70-76, 2017. DOI: $10.18389 /$ dearq20.2017.08

AMANN, Atxu; GRIGORIADOU, Magdalini; MEDINA, Ana. "\#MeTooArchitecture. Tácticas críticas feministas”. En Feminismo/s, 32, p. 205-229, diciembre 2018. Dosier monográfico: MAS-MES: Mujeres, Arquitectura y Sostenibilidad - Medioambiental, Económica y Social. DOI: 10.14198/fem.2018.32.08

ARIAS, Daniela; MUXÍ Zaida. "Aportaciones feministas a las arquitecturas y las ciudades para un cambio de paradigma." Hábitat y Sociedad, p. 5-12, 2018. DOI: 10.12795/HabitatySociedad.2018.i1 1.01

COMPTE, Florencio. "La constitución del campo disciplinar de la arquitectura en Guayaquil". Revista AUC, n. 38, p. 7-17, julio de 2017.

DURÁN BALLÉN, Sixto. A mi manera... Los años de Carondelet. Quito: Abya Yala, 2005.

EL COMERCIO. "Arquitectura y Urbanismo". El Comercio, 23/06/1959: Recorte de archivo familiar. Cortesía de Mónica León Arias.

EL COMERCIO. "El colegio de arquitectos cumple medio siglo." El Comercio, 08/06/2012.

EL TIEMPO. "Lupe Ibarra, la primera arquitecta graduada en Cuenca." El Tiempo, 26/10/2008.

GOETSCHEL, Ana María. Educación de las mujeres, maestras y esferas públicas. Quito en la primera mitad del siglo XX. Quito: Abya Yala, 2007.

LA MAÑANA. "Arquitectura en Ecuador, Ganadería en Uruguay: Ethel Arias". La Mañana, 1977: Recorte de archivo familiar. Cortesía de Mónica León Arias.

MOISSET, Inés. "Cien arquitectas en Wikipedia" De-arq (Universidad de los Andes), n. 20, p. 20-27, 2017. DOI: $10.18389 /$ dearq20.2017.02

MOLINA, Patricia; LAQUIDÁIN, Begoña. Arquitectura y género. Situación y perspectiva de las mujeres arquitectas en el ejercicio profesional. Instituto de la Mujer [online], 2009. Disponible en https:// docplayer.es/60482232-Arquitectura-y-genero.html

ORTIZ, Alfonso, et. al. Quito Guía de Arquitectura. Quito/Sevilla: Junta de Andalucía, 2004.

PEÑAHERRERA, Andrés. "Restauraciones del Palacio de Carondelet en el siglo XX". En: SALVADOR, Jorge (ed.). El Palacio de Carondelet. Quito: Academia Nacional de Historia, 1996. 
PERALTA, Evelia. "Arquitectas en la historia, breves ejemplos de su huella pionera". Revista Trama, Quito: Trama, 2016, p. 85.

PERALTA, Evelia; MOYA Rolando. “Los Pioneros y la Arquitectura moderna en Quito”. Revista Trama. Quito: Trama, 2011.

RANEA, Beatriz. Feminismos. Editorial Los Libros de la Catarata. Madrid: 2019.

VILLEGAS, Erika. La educación de las mujeres ecuatorianas a través de los Informes de Ministros de 1930 a 1940. Quito: Universidad Andina Simón Bolívar, 2013.

\section{Entrevistas realizadas por las autoras y otros colaboradores}

ARÍZAGA, Dora. Arquitectas ecuatorianas. Entrevista de María José FREIRE, Verónica ROSERO e Irina GODOY. Quito, (08/012019).

BARRAGÁN, Milton. Arquitectas ecuatorianas. Entrevista de Verónica ROSERO. Quito, (30/05/2019).

BLACIO, Marcela. Arquitectas ecuatorianas. Entrevista de María José FREIRE, Verónica ROSERO e Irina GODOY. Guayaquil, (21/03/2019).

CARCELÉN, Franklin. Arquitectas ecuatorianas. Entrevista de María José FREIRE. Quito, (8 de mayo de 2019).

DEL PINO, Inés. Arquitectas ecuatorianas. Entrevista de María José FREIRE, Verónica ROSERO e Irina GODOY. Quito, (04/02/2019).

IBARRA, Guadalupe. Arquitectas ecuatorianas. Entrevista de María José FREIRE, Verónica ROSERO e Irina GODOY. Cuenca, (22/01/2019).

LEÓN, Mónica. Entrevista a Mónica León, hija de Ethel Aria. Entrevista de Verónica ROSERO. Montevideo, (04/07/2018).

PERALTA, Evelia. Arquitectas ecuatorianas. Entrevista de María José FREIRE, Andrés CEVALLOS e Irina GODOY. Quito, (25/07/2018).

SOLANO, Ana. Arquitectas ecuatorianas. Entrevista de María José FREIRE, Verónica ROSERO e Irina GODOY. Guayaquil, (21/03/2019).

Verónica Alexandra Rosero Añazco (veronica.rosero.arq@uisek.edu.ec; varoseroa@uce.edu.ec) es doctora en Arquitectura y máster en Proyectos de Arquitectura y Ciudad (Universidad de Alcalá). Mención Doctorado Internacional (estancia en TU Delft). Arquitecta (Pontificia Universidad Católica del Ecuador). Investigadora, Universidad Internacional SEK. Profesora en las áreas de Diseño Arquitectónico y Teoría: Universidad Central del Ecuador. Publicaciones recientes: Demolición: el agujero negro de la modernidad (Editorial Diseño, Argentina), "Ensayo sobre la desigualdad de género en la arquitectura ecuatoriana" (Revista Ábaco, España)

María José Freire Silva (mjfreires@uce.edu.ec; uce.informacion1@uce.edu.ec) es arquitecta (Universidad Central del Ecuador) Máster en Urbanismo (Universidad Politécnica de Cataluña). Docente investigadora (Universidad Central del Ecuador). Línea de investigación: espacio público, movilidad, urbanismo, ciudad, género. Publicaciones: Quito: evolución de una política para el espacio público (ISSN 2339-6598). Tres "cosas urbanas" en HafenCity, Hamburg (ISSN 2339-6598).

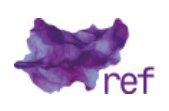




\section{COMO CITAR ESTE ARTÍCULO, DE ACUERDO CON LAS NORMAS DE LA REVISTA:}

Cómo citar este artículo de acuerdo con las normas de la revista: ROSERO AÑAZCO, Verónica Alexandra; FREIRE SILVA, María José. "Pioneras de la arquitectura ecuatoriana". Revista Estudos Feministas, Florianópolis, v. 28, n. 3, e71227, 2020.

\section{CONTRIBUCIÓN DE AUTORÍA}

Verónica Alexandra Rosero Añazco - estructuración del articulo, concepción, recolección de datos, análisis de los datos, elaboración del manuscrito, redacción y discusión de resultados.

María José Freire Silva - concepción, recolección de datos, análisis de los datos, elaboración del manuscrito, redacción y discusión de resultados.

Estudiantes Mishell Villalba y Daniela Hadatty (UCE), Gabriela Hinojosa y David Almeida (UISEK), y docentes Irina Godoy, Andrés Cevallos y Paulina Villamarín (UCE) y Néstor Llorca (UISEK) - colaboración para recolección de datos y entrevistas.

\section{FINANCIACIÓN}

Investigación financiada por la Dirección de Investigación e Innovación de la Universidad Internacional SEK, Quito, Ecuador, a través del proyecto "Teorización y diagnóstico del hábitat contemporáneo". La temática es de interés del Colegio de Arquitectos del Ecuador y del Museo de Arquitectura del Ecuador, por lo que una vez publicado el artículo, apoyarán con fondos y espacios para montaje de la exposición "Pioneras de la arquitectura ecuatoriana".

\section{CONSENTIMIENTO DE USO DE IMAGEN}

No se aplica.

\section{APROBACIÓN DE COMITÉ DE ÉTICA EN INVESTIGACIÓN}

No se aplica.

\section{CONFLICTO DE INTERESES}

No se aplica.

\section{LICENCIA DE USO}

Este artículo está licenciado bajo la Licencia Creative Commons CC-BY Internacional. Con esta licencia se puede compartir, adaptar, crear material para cualquier objetivo, siempre que se le atribuya la autoría.

\section{HISTORIAL}

Recibido el 29/01/2020

Presentado nuevamente el 08/07/2020

Aprobado el 23/07/2020 